\title{
Effect of stenosed and occluded coronary arteries on immediate and late myocardial uptake of thallium-201
}

\author{
D CLITSAKIS, C A LAYTON, W BATTERSBY, M JOHNS, A V STOCKLEY \\ From the Cardiac Department, The London Chest Hospital, and Department of Medical Physics, \\ Southend General Hospital
}

SUMMARY Exercise and redistribution myocardial scintigraphy using thallium-201 was compared with the left ventricular angiogram and with the presence of stenosis or occlusion of coronary arteries on angiography. Irreversible scintigraphic defects representing areas of myocardial infarction were found in all patients with occlusion of the left anterior descending artery but nearly one-third of patients with stenosis of that artery also showed evidence of infarction. For the right coronary or circumflex arteries the incidence of infarction was $82 \%$ with vessel occlusion and $57 \%$ with vessel stenosis. Of abnormally contracting segments on the left ventricular angiogram, $95 \%$ showed irreversible scintigraphic defects but $33 \%$ of normally contracting segments supplied by a diseased artery also showed this.

Myocardial infarction is not uncommon in patients with angina even in the absence of coronary occlusion. The incidence is underestimated by the left ventricular angiogram. These findings are of importance in the assessment of patients with coronary disease and their evaluation before coronary artery surgery.

Myocardial scintigraphy using thallium-201 is widely used in the assessment of patients with suspected coronary artery disease. ${ }^{1-6}$ The sensitivity of the method when compared with coronary angiography is good and when computer processing techniques are applied to scintigrams performed on exercise the sensitivity is excellent..$^{7-9}$ The myocardial distribution of thallium-201 immediately after intravenous injection is directly related to regional myocardial perfusion ${ }^{10}$ whereas after four hours the distribution of thallium-201 is a reflection of the relative size of the potassium pool between the heart and other organs and between different regions of the myocardium. This difference in the mechanisms of thallium-201 distribution has been used to separate areas of reversible ischaemia from myocardial infarcts by performing an initial scintigram during exercise and repeating the investigation after four hours without a further injection of thallium-201. ${ }^{45}$

This technique was used to assess the relative effects of stenosed and occluded coronary arteries on regional myocardial uptake of thallium-201 and therefore the relation between the vascular lesions and the

Received for publication 5 May 198 presence of previous myocardial infarcts. A comparison was also made of the scintigraphic findings and the left ventricular angiogram.

\section{Patients and methods}

Patients undergoing investigation for suspected coronary artery disease were studied by myocardial scintigraphy and coronary arteriography. Those with a normal arteriogram were subsequently excluded and the remaining 27 cases with lesions of at least $50 \%$ severity affecting at least one coronary artery were analysed. In each case scintigraphy was performed before the angiogram and was reported by an observer without knowledge of the angiographic findings.

A maximal treadmill exercise test was performed and thallium-201 injected either at the onset of angina or 45 seconds before completion of the test. In the former case exercise was continued at a reduced level for a further 45 seconds. Patients were then positioned for myocardial scintigraphy in the erect position in anterior, left anterior oblique $\left(45^{\circ}\right)$, and left lateral projections. Scintigrams were performed with a Nuclear Enterprises Mk V HR scintillation camera with a high resolution parallel hole collimator. Data were stored in a $64 \times 64$ matrix for subsequent 
processing using a Varian V76 computer. After four hours a further series of scintigrams was obtained using the same projections. The basic data were initially processed by executing a nine-point smoothing programme. The level of background was then evaluated by examining a series of profiles passing through the area of maximal myocardial activity. Having determined this level, background subtraction was then performed. Any area of myocardium showing $50 \%$ or less of maximal myocardial activity after processing was regarded as abnormal both in early perfusion scans or late redistribution scans.

Segmental analysis of the scintigrams was performed and the two groups identified. The first showed defects in either the anterior, apical, or anterolateral segments and the second showed defects in the inferior or posterior segments. Scintigraphic defects in the first category were correlated with lesions of the left anterior descending coronary artery and those in the second group were correlated with circumflex or right coronary artery lesions.

Coronary angiography was performed within two weeks of scintigraphy using the Sones technique. Cine-angiograms were recorded in multiple views and lesions of greater than $50 \%$ severity were regarded as significant. Left ventricular angiography was performed in the right anterior oblique projection after administration of sublingual isosorbide dinitrate to avoid performing the angiogram during ischaemia and thereby inducing transient disturbances of regional ventricular contraction. The left ventricular angiogram was described on the basis of a segmental analysis of contraction. Hypokinesis, akinesis, and dyskinesis were regarded as abnormal.

The relation between the scintigraphic findings and the nature of the coronary lesions was evaluated by the $\chi^{2}$ test corrected for small numbers. The relation between the scintigram and the left ventricular angiogram was assessed by the same method.

\section{Results}

Disease of three or more coronary arteries was found in 15 of the 27 patients studied. Disease of two vessels was found in seven patients and single vessel disease was present in the remaining five. Three patients also had a significant stenosis of the left main stem and for the purpose of this study have been categorised as having both left anterior descending and circumflex artery disease.

The left anterior descending artery was affected in 21 patients; in 15 of these there was a significant stenosis and in six patients the artery was occluded. Disease of the right coronary artery in the absence of circumflex disease was present in three cases; in two the vessel was occluded. The circumflex artery was diseased with a normal right coronary artery in five patients; the artery or a major lateral circumflex branch was stenosed in three and occluded in two. Disease of both the right coronary and circumflex arteries was present in 17 patients; in seven at least one vessel was occluded. Because of the small number of cases with right coronary or circumflex artery disease these groups have been combined.

Scintigraphic defects were seen during exercise in all cases in segments appropriate to the distribution of the coronary disease with the exception of one patient with an isolated $50 \%$ lesion of the left anterior descending artery in whom a normal scintigram was obtained.

Out of 17 occluded vessels only two were associated with reversible scintigraphic defects, the remaining 15 being irreversible. In contrast, the 29 stenosed arteries were associated with reversibility of the scintigraphic defect in 15 cases and an irreversible defect in 13 cases, one having no defect. An analysis of the type of scintigraphic defect in relation to the specific vessel involved showed that, for lesions of the left anterior descending artery (Table 1), occlusion was accompanied by irreversible defects in all six cases whereas in the 15 patients with stenosis only the defect was reversible in nine $(60 \%)$.

Reversible defects were found in six of 14 patients $(43 \%)$ with stenosis of the right coronary or circumflex arteries (Table 2). In eight the defect was irreversible. Where one or more of these vessels were occluded nine out of the 11 patients showed irreversible defects.

The segmental analysis of the left ventricular angiogram was compared with the scintigraphic findings (Table 3 ). In all cases abnormally contracting segments showed reduced thallium-201 activity on exercise. A total of 21 such segments were found in 15 patients. A further 24 segments in 17 patients which

Table 1 Left anterior descending artery

\begin{tabular}{lll}
\hline & \multicolumn{2}{l}{ Scintigraphic defect } \\
\cline { 2 - 3 } & Reversible & Irreversible \\
\hline Stenosed & 9 & 5 \\
Occluded & 0 & 6 \\
\hline
\end{tabular}

NB. One patient had a normal scan.

Table 2 Right coronary or circumflex arteries

\begin{tabular}{lll}
\hline & \multicolumn{2}{l}{ Scintigraphic defect } \\
\cline { 2 - 3 } & Reversible & Irreversible \\
\hline Stenosed & 6 & 8 \\
Occluded & 2 & 9 \\
\hline
\end{tabular}


Table 3 Left ventricular angiogram

\begin{tabular}{llc}
\hline & \multicolumn{2}{l}{ Segmental contraction } \\
\cline { 2 - 3 } & Normal & Abnormal \\
\hline Reversible defect & 16 & 1 \\
Irreversible defect & 8 & 20 \\
No defect & 9 & 0 \\
\hline
\end{tabular}

contracted normally were also associated with scintigraphic defects during exercise. Reversibility of the abnormal scintigram occurred in 16 of 17 segments with normal contraction. Conversely, only eight of 28 segments with irreversible defects contracted normally.

The extent of the scintigraphic defects in patients with normal and abnormal segmental contraction has been analysed when expressed as a reduction below $50 \%$ of maximal myocardial activity for that patient. No difference was found in the severity of the defects in segments irrespective of the presence or absence of contraction abnormality.

\section{Discussion}

Although the factors determining the distribution of thallium-201 within the myocardium after intravenous injection were described some years ago $^{11}$ it is only recently that this knowledge has been used to differentiate between reversible and irreversible ischaemic segments. ${ }^{4}$ Since the immediate myocardial uptake of thallium-201 is dependent on myocardial perfusion $^{11}$ the early scintigram can be used to identify areas of diminished perfusion. The scintigrams obtained four hours later reflect the redistribution of thallium-201 in proportion to the relative size of the potassium pool in different areas. It has been shown experimentally that the redistribution of thallium-201 is independent of continuing myocardial ischaemia. ${ }^{12}$

The sensitivity of the early scintigram in detecting myocardial ischaemia is increased by performing the early perfusion scintigram during exercise and is further improved by applying computer processing techniques/ to the scintigraphic data. ${ }^{7-9}$ These techniques are used to reduce the effect of relatively high levels of background activity which tend to mask the myocardial areas of reduced activity. ${ }^{1314}$ The correct level of background to be subtracted cannot easily be evaluated accurately because of the summation of counts obtained from the heart and overlying lung and chest wall. It is, however, of great importance that the subtraction level closely approximates the true background since excessive subtraction will result in apparent myocardial defects which are not in fact significant. Similarly, too low a level of subtraction will reduce the sensitivity of the scintigram.
In order to overcome this difficulty resulting from the wide point-to-point variation in background adjacent to the heart we have used a smoothing programme before determining the level of background to be subtracted. This results in more uniform levels of background and therefore allows a more reliable assessment of the required subtraction level. The technique also permits the application of rigid criteria of abnormality.

Our earlier observations ${ }^{7}$ in a series of 65 patients with coronary disease have shown that segments with activity of less than $50 \%$ of the most active myocardial segment are likely to be supplied by a diseased vessel. The sensitivity for the detection of coronary disease was $\mathbf{9 7 \%}$ using the processing steps described. The specificity could not be determined in that study since the prevalence of coronary disease was $100 \%$. If segmental activity was related to specific vessels, however, as in the present study, the sensitivity of the method was $94 \%$ and the specificity was $96 \%$. In an unpublished series of 500 patients with a low prevalence of coronary disease $(62 \%)$, as one would expect the sensitivity fell to $85 \%$ when relating defects to specific vessels and the specificity fell to $90 \%$.

While these results may reflect deficiencies in the resolution and discrimination of the system other possible explanations for "false" positive and negative results may be advanced. For example, in patients with multiple vessel disease, the exercise test may be limited by symptoms resulting from ischaemia developing in the territory supplied by one diseased vessel before the segments supplied by other, perhaps less seriously affected, arteries are significantly ischaemic also. The scintigram under these circumstances may underestimate the extent of the coronary disease. This merely emphasises that the thallium scintigram is a reflection of myocardial perfusion and is not directly related to coronary stenosis. Nevertheless in the present study of a selected group of patients only one normal scan was obtained.

The smoothing results in an artificially uniform activity profile across the myocardium as well as background, but, on the basis of the number of matrix points covered by the left ventricle and the use of a nine-point smoothing programme, it can be shown that any scintigraphic defect involving at least $2 \%$ of the total myocardial area will still be invariably identified after smoothing.

The identification of areas of myocardial infarction is important in the assessment of patients with coronary artery disease, particularly when surgical treatment is being considered. The left ventricular angiogram has a poor sensitivity for the detection of infarcts. Perfusion and redistribution thallium-201 scintigraphy offers a method by which previous infarction can be reliably identified and distinguished from reversible 
ischaemia. In the territory of the left anterior descending artery occlusion was always associated with infarction, but even in the absence of total occlusion infarction was present in nearly a third of cases. For circumflex and right coronary lesions the pattern is less clear, with infarction as the more common finding even in the absence of occlusion. The differences found between left anterior descending artery disease and disease of the other vessels may be the result in part of the variable distribution of the circumflex and right coronary artery systems. Furthermore, no analysis of the effectiveness of the collateral circulation has been made though this is known to be of importance. ${ }^{15}$

Infarction in the absence of coronary occlusion is well recognised both in the early stages of acute infarction and in the course of later investigation. The results of this study indicate that this situation is more common than has formerly been supposed. This may arise as the result of recanalisation of a previously occluded vessel. Alternatively, infarction may result from a critical reduction in flow in a non-occluded vessel or as the result of coronary arterial spasm in an already diseased vessel. The relation between infarction and coronary occlusion remains in doubt.

The poor sensitivity of the left ventricular angiogram has been confirmed by this study. Though over $95 \%$ of abnormally contracting segments showed irreversible scintigraphic defects this was also found in a third of the normally contracting segments. The regular use of isosorbide dinitrate before left ventricular angiography may have reduced the sensitivity of the angiogram in the detection of abnormal wall motion. We feel, however, that when assessing patients for possible coronary artery surgery it is more important to avoid the possibility of stress-induced regional contraction abnormalities resulting in a misleading assessment of left ventricular function.

These results indicate the value of exercise and redistribution thallium-201 scintigraphy for the detection of reversible and irreversible ischaemic segments. The number of patients included in this study is small, and only 18 of these have subsequently undergone coronary artery bypass surgery. It is not therefore possible at this stage to assess the prognostic value of these data, but the method should prove useful in planning coronary artery bypass surgery and in following the course of patients with coronary artery disease treated either medically or by operation.

\section{References}

1 Bailey IK, Griffith LSC, Rouleau J, Strauss HW, Pitt B. Thallium-201 myocardial perfusion imaging at rest and during exercise. Circulation 1977; 55: 79-97.

2 Botvinick EH, Taradash MR, Shames DM, Parmley
WW. Thallium-201 myocardial perfusion scintigraphy for the clinical clarification of normal, abnormal and equivocal electrocardiographic stress tests. Am $\mathcal{F}$ Cardiol 1978; 41: 43-51.

3 Ritchie JL, Zaret BL, Strauss HW, et al. Myocardial imaging with thallium-201: a multicenter study in patients with angina pectoris or acute myocardial infarction. Am $\mathcal{F}$ Cardiol 1978; 42: 345-50.

4 Pohost GM, Zir LM, Moore RH, McKusick KA, Guiney TE, Beller GA. Differentiation of transiently ischemic from infarcted myocardium by serial imaging after a single dose of thallium-201. Circulation 1977; 55: 294302.

5 Blood DK, McCarthy DM, Sciacca RR, Cannon PJ. Comparison of single-dose and double-dose thallium201 myocardial perfusion scintigraphy for the detection of coronary artery disease and prior myocardial infarction. Circulation 1978; 58: 777-88.

6 Leppo J, Yipintsoi T, Blankstein R, et al. Thallium-201 myocardial scintigraphy in patients with triple-vessel disease and ischemic exercise stress test. Circulation 1979; 59: 714-21.

7 Layton CA, Stockley A. Computer processed thallium201 scintigrams during and 4 hours after maximal exercise. Significance of stenosed and occluded vessels (abstract). Br Heart f 1979; 41 : 368.

8 Peterson K, Tsuji J, Schelbert H, Sperling M, Ashburn W. Improved diagnosis of a coronary artery disease during exercise test using a computer processed thallium201 image (abstract). Circulation 1976; 53 \& 54, suppl II: 207.

9 Fletcher JW, Walter KE, Witzum KF, et al. Diagnosis of coronary artery disease with $201 \mathrm{Tl}$ : computer analysis of myocardial perfusion images. Radiology 1978; 128: 423-7.

10 Maseri A, Parodi O, Severi S, Pesola A. Transient transmural reduction of myocardial blood flow, demonstrated by thallium-201 scintigraphy, as a cause of variant angina. Circulation 1976; 54: 280-8.

11 Strauss HW, Harrison K, Langan JK, Lebowitz E, Pitt B. Thallium-201 for myocardial imaging-relation of thallium-201 to regional myocardial perfusion. Circulation 1975; 51: 641-5.

12 Schwartz JS, Ponto R, Carlyle P, Forstrom L, Cohn JN. Early redistribution of thallium-201 after temporary ischemia. Circulation 1978; 57: 332-5.

13 Goris ML, Daspits G, McLaughlin P, Kriss JP. Interpolative background subtraction. $\mathcal{F}$ Nucl Med 1976; 17: 744-7.

14 Narahara KA, Hamilton GW, Williams DL, Gould KL. Myocardial imaging with thallium-201-an experimental model for analysis of the true myocardial and background image components. F Nucl Med 1977; 18: 781-6.

15 Wainwright R, Maisey MN, Edwards AC, Sowton E. Functional significance of coronary collateral circulation during dynamic exercise evaluated by thallium-201 myocardial scintigraphy. Br Heart $\mathcal{f} 1980$; 43: 47-55.

Requests for reprints to Dr Clive Layton, Cardiac Department, The London Chest Hospital, Bonner Road, London E2 9JX. 